УДК 532.612 .4

\title{
Instability of a Two-layer System with Deformable Interfaces under Laser Beam Heating
}

\author{
Victoria B. Bekezhanova* \\ Institute of Computational Modeling SB RAS \\ Academgorodok, 50/44, Krasnoyarsk, 660036 \\ Russia \\ Olga N. Goncharova ${ }^{\dagger}$ \\ Altai State University \\ Lenina, 61, Barnaul, 656049 \\ Russia \\ Natalia A. Ivanova ${ }^{\ddagger}$ \\ Denis S. Klyuev $\$$ \\ Tyumen State University \\ Volodarskogo, 6, Tyumen, 625003 \\ Russia
}

Received 02.04.2019, received in revised form 03.05.2019, accepted 11.06.2019

New non-standard problem of thermocapillary convection is studied to analyze the flows arising in a twolayer system under action of an intense thermal exposure on the free boundary by a laser beam. Characteristics of the physical experiments are presented. Parameters of the experiments are the ratio of the liquid layer thicknesses, the types of working liquids, the absorption coefficients of media. Special attention is given to the study of the influence of the system geometry when changing the thickness for one of the liquid layers. Theoretical study of the thermocapillary convection includes development of the mathematical model tested on the basis of new physical experiment data and of the effective numerical algorithm to calculate basic characteristics. The occurrence of the decaying oscillations, which first experimentally discovered by the authors, and the evolution of the interfaces and layers are investigated. The results of numerical study of structure and nature of convective flows in the horizontal two-layer liquid-liquid systems of the type "silicone oil-glycerin", and comparison of the experimental and theoretical data allow one to validate the developed mathematical model, to analyze the peculiarities of heat and mass transfer in the two-layer system induced by the action of a local heat source at the free boundary.

Keywords: thermocapillary convection, two-layer system, interface, free surface, local thermal load.

DOI: 10.17516/1997-1397-2019-12-5-543-550.

\section{Introduction. Experimental investigations}

New physical experiments are performed in order to study features of onset and development of the thermocapillary convection in the systems of immiscible liquids subjected to the point

\footnotetext{
*vbek@icm.krasn.ru

†gon@math.asu.ru

$\ddagger_{n}$.ivanova@utmn.ru

§kludis_938@mail.ru

(C) Siberian Federal University. All rights reserved
} 
laser exposure. The systems comprise glycerin (or ethylene glycol, benzyl alcohol) in the bottom layer and silicone oil of different viscosity in the top layer. It was established experimentally that in the systems like "glycerin - silicone oil" and "ethylene glycol-silicone oil" the thermocapillary rupture of the upper layer or stable thermocapillary groove can be observed. Besides the gap and recess in the system "benzyl alcohol-silicone oil" the regime of dynamic instability of the upper layer (or so-called damped thermocapillary oscillations) is observed in a certain range of change in the upper layer thickness $l_{2}$. The enhanced accuracy of the experimental measurements for various thermophysical characteristics of the fluids, as well as modern methods of mathematical modeling, allow one to study the velocity fields near the boundaries and in the surface layers. Therefore, the phenomena of heat and mass transfer can be properly taken into account in modelling, and dominant mechanisms that govern the nature and character of the arising flow regimes can be correctly determined.

We will proceed from the following experiments described partially in [1]. Profiles of the thermocapillary (TC) deformations and stationary TC rupture of the upper layer in the twolayer liquid system were measured with use of the laser scanning sheet method depending on $l_{2}$ for the liquid-liquid system polydimethylsiloxane-10 (PDMS-10)-ethylene glycol with a heat source at the interface. It was established that the TC gap occurs at almost all values of the layer thickness $\left(l_{2} \sim 400-900\right.$ microns, hereafter referred to as $\left.\mu \mathrm{m}\right)$. With an increase of the upper layer thickness the TC rupture diameter is decreased as well as the curvature radius of the convex lower layer deformation in zone of thermal action. The system with clear hexadecane as upper liquid and laser radiation absorbing glycerin as lower one was used also. For this pair of working media it was shown that change in the lower layer thickness $l_{1}$ from 1 to $5 \mathrm{~mm}$ at a constant thickness of the top coating $l_{2}=500 \mu \mathrm{m}$ does not affect the TC rupture profile of the upper layer and the lower layer raising height in the zone of TC rupture (Fig. 1).
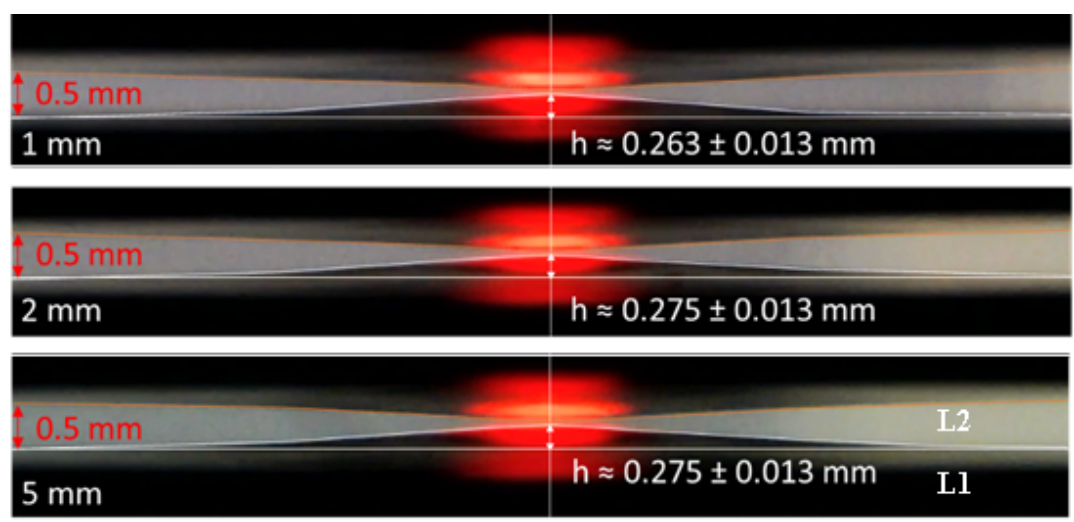

Fig. 1. Profile of the interface deformation between lower $\left(L_{1}\right)$ and upper $\left(L_{2}\right)$ layers (side-view) with $l_{1}=1,2,5 \mathrm{~mm}$. Here $h$ denotes the lower layer raising height in zone of the laser beam action

For fixation of the stationary diameter of the TC layer rupture it is required a maintenance of minimal threshold temperature difference $\Delta T_{s}$ between the TC rupture edge and periphery. Upon that, value of $\Delta T_{s}$ is significantly less than the layer rupture temperature $\Delta T_{r}$. If the upper layer thickness $l_{2}$ is diminished, then magnitudes $\Delta T_{s}$ and $\Delta T_{r}$ will be decreased. Time of full relaxation of the TC rupture ("healing" of the layer by turning off the pump laser) in the two-layer system is determined by the decay time of $\Delta T_{s}$. 
In the present work we develop the mathematical model of the thermocapillary convection in a two-layer system of liquids being under action of a local point heating on the basis of the classical convection equations [2] and numerical algorithm based on the Ovcharova's method idea [3] that allows one to find correctly the shapes of the deformable interfaces having parts with strongly changing curvature. Theoretical study of the problem of convection in a two-layer system with the determination of deformable interface positions is extremely difficult. The first numerical result that was obtained with use of the working parameters close to the experimental ones confirmed the qualitative coincidence with the results of experiments. It should be noted that all known theoretical investigations of dynamics of systems with the interface under local heating have been carried out within the framework of the thin layer approximation. However, this approach does not allow one to take fully into account the influence of the vertical velocity component and the contribution of convective terms to the formation of the flow structures, both in terms of hydrodynamic and thermal aspects. The Oberbeck-Boussinesq model of convection have been used for the first time to study the dynamics of a two-layer liquid - gas system subjected to local thermal load in [4]. The features of the thermocapillary flows in the two-phase system caused by action of the point heaters arranged on the outer fixed solid boundaries of the plane horizontal cuvette were analyzed. The structure of the temperature and velocity fields, and forms of the thermocapillary deformations of the interface were calculated with the help of the original numerical method [5].

\section{Equations of convection}

Let the Cartesian coordinate system be chosen so that the gravity acceleration vector $\mathbf{g}$ is directed opposite to the $O y$ axis $(\mathbf{g}=-g \mathbf{j}, \mathbf{j}$ is the unit vector of $O y$ ). Two immiscible viscous incompressible liquids fulfill a rectangular cavity. The upper boundary of this system $\Gamma_{b}$ is a free boundary defined by equation $y=f_{b}(t, x)$. Liquid domains $L_{1}$ and $L_{2}$

$$
\begin{gathered}
L_{1}=\left\{(x, y): 0<x<X, 0<y<f_{0}(t, x)\right\}, \\
L_{2}=\left\{(x, y): 0<x<X, f_{0}(t, x)<y<f_{b}(t, x)\right\},
\end{gathered}
$$

are separated by the thermocapillary interface $\Gamma_{0}$ defined by equation $y=f_{0}(t, x)$. Outer boundaries $x=0, x=X, y=0$ of the domains $L_{1}$ and $L_{2}$ are the fixed rigid impermeable walls.

The convective flow of $j$-th medium $(j=1,2)$ is described by the Oberbeck-Boussinesq approximation of the Navier-Stokes equations [2]. The governing equations written in the nondimensional variables for the required functions $\psi$ (stream function), $\omega$ (vorticity) and $T$ (temperature) take the following form:

$$
\begin{gathered}
\partial_{t} \omega_{j}+\partial_{x}\left(\omega_{j} \partial_{y} \psi_{j}\right)-\partial_{y}\left(\omega_{j} \partial_{x} \psi_{j}\right)=\operatorname{Re}_{j}^{-1} \Delta \omega_{j}+\operatorname{Gr}_{j} \operatorname{Re}_{j}^{-2} \partial_{x} T_{j} \\
\Delta \psi_{j}+\omega_{j}=0, \partial_{t} T_{j}+\partial_{x}\left(T_{j} \partial_{y} \psi_{j}\right)-\partial_{y}\left(T_{j} \partial_{x} \psi_{j}\right)=\operatorname{Pr}_{\mathrm{j}}^{-1} \operatorname{Re}_{\mathrm{j}}^{-1} \Delta T_{j}
\end{gathered}
$$

Here (and subsequently) $j=1,2$ relate to the lower and upper liquids, respectively. The problem is characterized by the following dimensionless parameters: the Reynolds numbers $\operatorname{Re}_{\mathrm{j}}=u_{*} h / \nu_{j}$, the Prandtl numbers $\operatorname{Pr}_{\mathrm{j}}=\nu_{j} / \chi_{j}$, the Grashof numbers $\mathrm{Gr}=\beta_{j} T_{*} g h^{3} / \nu_{j}^{2}$, where $\nu_{j}, \chi_{j}, \beta_{j}$ are the kinematic viscosity, thermal diffusivity and thermal expansion coefficients of $j$-th fluid, respectively. The linear size of the flow domain in the $y$-direction $h$ will be chosen for the characteristic length. The characteristic values of velocity and temperature are denoted as $u_{*}$ 
and $T_{*}$. The required functions are associated with the original unknown functions through usual relations: $u_{j}=\partial_{y} \psi_{j}, v_{j}=-\partial_{x} \psi_{j}, \omega_{j}=\partial_{x} v_{j}-\partial_{y} u_{j}$. Here, $u_{j}, v_{j}$ are the components of velocity vector $\mathbf{v}_{j}$.

The fluid flows and heat transfer processes in each of the liquid layers $L_{j}$ will be investigated numerically with use of convection equations (1.1), (1.2).

\section{Surface tension on deformable boundaries $\Gamma_{0}$ and $\Gamma_{b}$}

The interface conditions are formulated in terms of $\omega-\psi$ on the basis of the conservation laws and some additional assumptions [6]. The interfaces $\Gamma_{b}$ and $\Gamma_{0}$ are characterized by their surface tension coefficients $\sigma_{2}(T)$ and $\widetilde{\sigma}(T)$, respectively. To define the surface tension $\widetilde{\sigma}(T)$ for the "liquid - liquid" boundary $\Gamma_{0}$ we suppose that liquids in the system are under the conditions of intermutual saturation. Then, the Antonov rule [7] can be used: $\widetilde{\sigma}(T)=\sigma_{1}(T)-\sigma_{2}(T)$. Here $\sigma_{j}(T)=\sigma_{j 0}-\sigma_{j_{T}}\left(T_{j}-T_{0}\right)$ is the surface tension for $j$-th liquid on the boundary with air or own vapor, values $\sigma_{j 0}, \sigma_{j T}$ are the positive constants, $\sigma_{j T}$ is the temperature coefficient of surface tension for $j$-th liquid on the boundary with air or own vapor. In the non-dimensional form the relation for $\widetilde{\sigma}(T)$ is written as follows: $\widetilde{\sigma}(T)=\widetilde{\sigma}_{0}-\left(\mathrm{Ma}_{1} \mathrm{Ca}_{1}-\mathrm{Ma}_{2} \mathrm{Ca}_{2}\right)\left(T-T_{0}\right)$, where $\tilde{\sigma}_{0}=\left(\sigma_{10}-\sigma_{20}\right) / \sigma_{*},\left(\sigma_{*}\right.$ is the characteristic value of surface tension, for example, $\left.\sigma_{*}=\sigma_{10}\right)$, $\mathrm{Ma}_{j}=\sigma_{j T} T_{*} /\left(\rho_{j} u_{*} \nu_{j}\right)$ is the Marangoni number, $\mathrm{Ca}_{j}=\rho_{j} u_{*} \nu_{j} / \sigma_{*}$ is the capillary number, $\rho_{j}$ is the $j$-th liquid density. The previous notations for non-dimensional surface tension of the interface and reference value $T_{0}$ are kept.

\section{Boundary conditions}

\subsection{Interface conditions on $\Gamma_{0}$}

Consider the interface $y=f_{0}(t, x)$ between the lower and upper layers and define the unit tangent and normal vectors on the interface

$$
\mathbf{s}=\left(1 / \sqrt{1+\left(f_{0}\right)_{x}^{2}},\left(f_{0}\right)_{x} / \sqrt{1+\left(f_{0}\right)_{x}^{2}}\right), \quad \mathbf{n}=\left(-\left(f_{0}\right)_{x} / \sqrt{1+\left(f_{0}\right)_{x}^{2}}, 1 / \sqrt{1+\left(f_{0}\right)_{x}^{2}}\right),
$$

where the following denotation are used: $\left(f_{0}\right)_{x}=\partial_{x} f_{0},\left(f_{0}\right)_{x}^{2}=\left(\partial_{x} f_{0}\right)^{2}$. For the lower liquid in $L_{1}, \mathbf{n}$ is the unit vector of the outer normal to the interface between the liquids. The continuity conditions of temperature and heat fluxes are valid at the interface $\Gamma_{0}: T_{1}=T_{2}, \partial_{n} T_{1}-\kappa \partial_{n} T_{2}=0$, where $\kappa=\kappa_{2} / \kappa_{1}$ is the ratio of coefficients of liquid thermal conductivities.

Assuming a fulfillment of the continuity of velocity on the interface (or the equality of the tangential velocities of liquids at their common interface $\Gamma_{0}$ and the volume preserving conditions for each medium), we obtain the following conditions for $\psi_{j}$ functions at this interface: $\psi_{1}=\psi_{2}$, $\partial_{n} \psi_{1}-\partial_{n} \psi_{2}=0$.

The kinematic and dynamic conditions on the interface $\Gamma_{0}$ in terms of $\omega-\psi$ are written in the following form

$$
\begin{gathered}
\left(f_{0}\right)_{t}+\sqrt{1+\left(f_{0}\right)_{x}^{2}} \partial_{s} \psi_{1}=0, \\
\omega_{1}-\rho \nu \omega_{2}=F_{1}(t, x), \\
\partial_{n} \omega_{1}-\rho \nu \partial_{n} \omega_{2}=F_{2}(t, x),
\end{gathered}
$$




$$
\begin{gathered}
F_{1}=\mathrm{Ma} \partial_{s} T+2(1-\rho \nu)\left(\partial_{s} v_{n}+v_{s} / R\right), \\
F_{2}(t, x)=-2\left[\partial_{s}\left(\partial_{n} v_{n}\right)_{1}-\rho \nu \partial_{s}\left(\partial_{n} v_{n}\right)_{2}\right]+2\left[(1-\rho \nu) \partial_{s}\left(\left(f_{0}\right)_{x} v_{s} / R_{0}\right)\right]+ \\
+\left(1 / \mathrm{Ca}_{1}\right) \partial_{s}\left[\left(1-\mathrm{Ma}_{1} \mathrm{Ca}_{1} T\right) / R_{0}\right]-\left(\rho \nu / \mathrm{Ca}_{2}\right) \partial_{s}\left[\left(\left(\sigma_{20} / \sigma_{*}\right)-\mathrm{Ma}_{2} \mathrm{Ca}_{2} T\right) / R_{0}\right]+ \\
+\left[\left(\left(\mathrm{Gr}_{1} / \operatorname{Re}_{1}\right)-\rho \nu\left(\mathrm{Gr}_{2} / \operatorname{Re}_{2}\right)\right) T\right]\left(f_{0}\right)_{x} / \sqrt{1+\left(f_{0}\right)_{x}^{2}}+\operatorname{GaRe}_{1}(1-\rho)\left(f_{0}\right)_{x} / \sqrt{1+\left(f_{0}\right)_{x}^{2}}+ \\
+\operatorname{Re}_{1}\left[(\rho-1) \partial_{t} v_{s}+(\rho-1) v_{s} \partial_{s} v_{s}+(1-\rho)\left(f_{0}\right)_{x} v_{n}^{2} / R_{0}+v_{n}\left(\omega_{2}-\rho \omega_{1}\right)\right] .
\end{gathered}
$$

Here $\left(f_{0}\right)_{t}=\partial_{t} f_{0}, T$ is the common value of the temperature on $\Gamma_{0}, v_{s}, v_{n}$ are the tangent and normal components of the velocity for points lying on the interface $y=f_{0}(x, t)$, they are common for both liquids on $\Gamma_{0}, R_{0}$ is the interface curvature radius $\left(1 / R_{0}=\left(f_{0}\right)_{x x} /\left(1+\left(f_{0}\right)_{x}^{2}\right)^{3 / 2}\right)$, $\left(f_{0}\right)_{x x}=\partial_{x}\left(\partial_{x} f_{0}\right), \rho=\rho_{2} / \rho_{1}, \nu=\nu_{2} / \nu_{1} ; \mathrm{Ga}=g h / u_{*}^{2}$ is the Galileo number.

\subsection{Free boundary conditions on $\Gamma_{b}$}

The unit tangent and normal vectors on the free boundary $y=f_{b}(t, x)$ are determined with the help of following relations:

$$
\mathbf{s}=\left(1 / \sqrt{1+\left(f_{b}\right)_{x}^{2}},\left(f_{b}\right)_{x} / \sqrt{1+\left(f_{b}\right)_{x}^{2}}\right), \quad \mathbf{n}=\left(-\left(f_{b}\right)_{x} / \sqrt{1+\left(f_{b}\right)_{x}^{2}}, 1 / \sqrt{1+\left(f_{b}\right)_{x}^{2}}\right),
$$

where $\left(f_{b}\right)_{x}=\partial_{x} f_{b},\left(f_{b}\right)_{x}^{2}=\left(\partial_{x} f_{b}\right)^{2}$. The temperature relations at the interface $\Gamma_{b}$ should provide the conditions of local heating. Assume that temperature is given as $T=T_{b}(t, x, y)$ for all $t \in\left[0, t_{\text {end }}\right], x \in\left[x_{0}-\varepsilon, x_{0}+\varepsilon\right]\left(x_{0}=X / 2\right)$ and $y=f_{b}(t, x)$. Let the condition of heat insulation of free boundary be valid for other parts of free boundary $\Gamma_{b}$, where $x \in\left[0, x_{0}-\varepsilon\right) \cup\left(x_{0}+\varepsilon, X\right]$ and $y=f_{b}(t, x): \partial_{n} T_{2}=0$.

The conditions of continuity of the total velocity vector on $\Gamma_{b}$ and of the volume preserving the upper liquid lead to the following relations for the stream function $\psi_{2}$ :

$$
\psi_{2}=\psi_{g}, \quad \partial_{n} \psi_{2}-\partial_{n} \psi_{g}=0 .
$$

Without loss of generality one can set $\psi_{g}=0$ in (3.1), assuming that a gas above the free boundary is a passive media, and considering $\Gamma_{b}$ as the material surface and the streamline for the upper fluid filling domain $L_{2}$.

The kinematic and dynamic conditions at $\Gamma_{b}$ written in terms of $\omega-\psi$ have the form:

$$
\begin{gathered}
\left(f_{b}\right)_{t}+\sqrt{1+\left(f_{b}\right)_{x}^{2}} \partial_{s} \psi_{2}=0, \\
\omega_{2}=2\left(v_{s} / R+\partial_{s} v_{n}\right)+\mathrm{Ma}_{2} \partial_{s} T_{2}, \quad \partial_{t} v_{s}+v_{s} \partial_{s} v_{s}=2 \partial_{s}^{2} v_{s}+F(t, x), \\
F(t, x)=-\partial_{n} \omega_{2}-2 \partial_{s}\left(v_{n} / R_{b}\right)+\left(1 / \mathrm{Ca}_{2}\right) \partial_{s}\left[\left(\left(\sigma_{20} / \sigma_{*}\right)-\mathrm{Ma}_{2} \mathrm{Ca}_{2} T_{2}\right) / R_{b}\right]+v_{n} \omega_{2}+\left(f_{b}\right)_{x} v_{n}^{2} / R_{b} .
\end{gathered}
$$

Here $v_{s}, v_{n}$ are the tangent and normal components of the velocity for points lying on the interface $y=f_{b}(x, t), R_{b}$ is the free boundary curvature radius, $1 / R_{b}=\left(f_{b}\right)_{x x} /\left(1+\left(f_{b}\right)_{x}^{2}\right)^{3 / 2}$, $\left(f_{b}\right)_{x x}=\partial_{x}\left(\partial_{x} f_{b}\right)$.

\section{Fluid flow regimes and deformations of the interfaces}

Numerical solution of the convection onset problem leads to determination of the velocity and temperature fields, and to computation of positions of the free boundary and interface. Without description of the numerical procedure to solve the problem formulated in 
Sec. 1 we have to note that it is based on the method developed in [3]. Here we present some results of calculations for "glycerin-silicone oil" system with the temperature distribution of the Gaussian type in zone of laser beam action. Influence of thermal load intensity on the flow pattern, heat transfer processes and character of the thermocapillary deformations of the interface and free boundary have been investigated. Physicochemical parameters in the CGS unit system and values of non-dimensional similarity criteria for the "glycerin-silicon oil" system are presented below in the order $\{$ glycerin (1), silicon oil (2)\}, respectively: $\rho=\{1.25,0.935\} \mathrm{g} / \mathrm{cm}^{3} ; \nu=\{1.44,0.1\} \mathrm{cm}^{2} / \mathrm{s} ; \beta=\{0.00061,0.00108\} \mathrm{K}^{-1}$; $\sigma=\{62.5,20.2\}$ dyne $/ \mathrm{cm} ; \sigma_{T}=\{0.0598,0.0697\} \mathrm{g} / \mathrm{cm}^{2} \cdot \mathrm{K} ; \kappa=\{28000,13400\} \mathrm{g} \cdot \mathrm{cm} /\left(\mathrm{s}^{3} \cdot \mathrm{K}\right) ;$ $c_{p}=\left\{2.5 \cdot 10^{7}, 1.498 \cdot 10^{7}\right\} \mathrm{cm}^{2} /\left(\mathrm{s}^{2} \cdot \mathrm{K}\right) ; \chi=\{0.0009,0.00096\} \mathrm{cm}^{2} / \mathrm{s}$. The two-layer system is in the terrestrial conditions and $g=981 \mathrm{~cm} / \mathrm{s}^{2}$. The values of the characteristic temperature drop $T_{*}$ and characteristic length $h$ are equal to $T_{*}=10 \mathrm{~K}$ and $h=1 \mathrm{~cm}$; the characteristic velocity $u_{*}$ is chosen to be equal to $1.44 \mathrm{~cm} / \mathrm{s}$ so that the Reynolds number of lower liquid will be equal to 1 . Calculations are carried out with the following values of dimensionless parameters: $\operatorname{Re}=\{1,14.4\} ; \operatorname{Pr}=\{1600,104.167\} ; \mathrm{Gr}=\{2.886,1059.48\}$, $\mathrm{Ga}=473.09$; $1 / \mathrm{Ca}=\{24.09,464.2\}\left(\right.$ at $\left.\sigma_{*}=\sigma_{10}\right) ; \mathrm{Ma}=\{0.231,5.177\}$. In the presented case an initial state is determined as follows: the liquids are at rest, the interface between them and upper free boundary are flat; the thicknesses of both layers are equal to $0.5 \mathrm{~cm}$; the cavity length is $X=20 \mathrm{~cm}$. The size of a heating zone on free boundary is equal to $3 \mathrm{~cm}$. The beam is directed to the free boundary point with abscissa $X / 2$. By local heating simulation the temperature distribution $T_{b}(t, x, y)$ is set as follows for $t>0$ and $y=f_{b}(t, x): T_{b}=T_{\text {heat }}(t, x)=A(t) \sin \varpi(x-\underline{x}), x \in[\underline{x}, \bar{x}]$, where the frequency is $\varpi=\pi /(\bar{x}-\underline{x})$ and the amplitude takes the values $A(t)=\{0.1,0.25,0.5,0.75,1\}$ when $t$ changes on intervals $\left(t_{i}, t_{i+1}\right](i=0, \ldots, 5)$, respectively, and remains to be equal $A(t)=1$ for $t>t_{5}$ (here $\bar{x}=11.5, \underline{x}=8.5 ; t_{0}=0, t_{i+1}=t_{i}+10$ ).

Results of the numerical simulation obtained in the framework of suggested mathematical model allows one to predict behavior of the system under study, upon that the numerical results are in reasonably good agreement with experimental data. Form of the free boundary and interface, and the distribution of the velocity and temperature fields in the system "glycerinsilicone oil" observed $90 \mathrm{~s}$ after start of heating are presented in Fig. 2. A stable thermocapillary deflection is formed on the free boundary due to action of laser beam (Fig. 2(a)). Convex thermocapillary deformation ("hump") appears on the interface between lower and upper liquids (Fig. 2(b)). Similar type of the interface deformation is caused by the significant influence of the viscous properties of the upper fluid. With time the amplitudes of deformations on both deformable boundaries gradually increase.

Thermocapillary spreading the liquid from hot domain to cold one in the upper layer is induced by the local heating and two main vortices with opposite circulation appear in zone of laser beam action. For late time with increasing the intensity of thermal load additional small swirls are formed (Fig. 2(c)). Thus, heat transfer is provided by the liquid motion caused by the thermocapillary effect.

\section{Conclusions}

Suggested approach to describe dynamics heat and mass transfer and character of deformations for the free boundary and internal interface in two-layer system subjected to local heating from the free boundary provides good qualitative agreement between numerical simulation results and experimental data. It allows one to predict the possible flow structure and to analyze nature of phenomena observed in the corresponding experiments. 

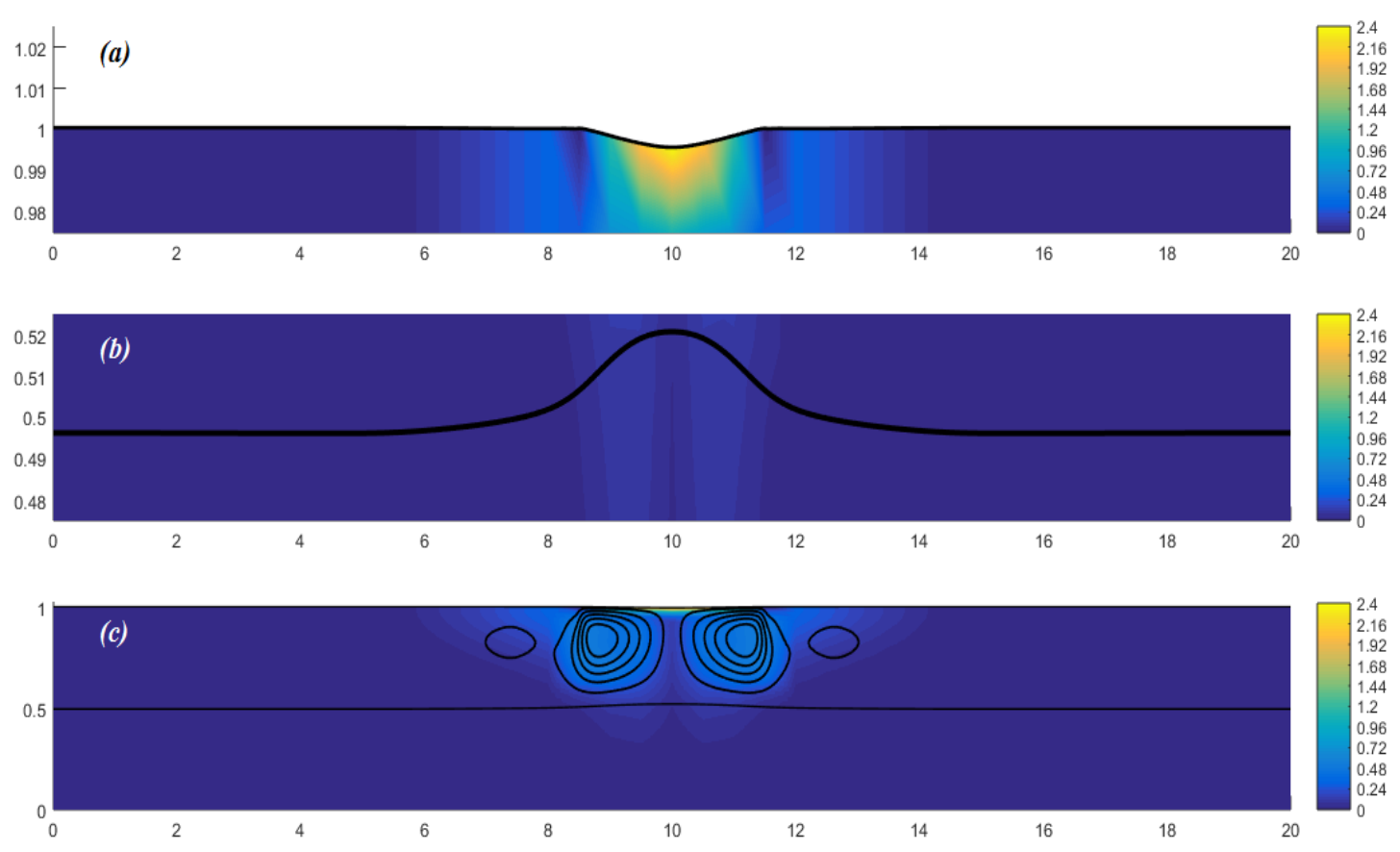

Fig. 2. Profiles of the free boundary (a) and interface (b) deformations, and pattern of the thermal and hydrodynamical fields (c) at $t=90 \mathrm{~s}$

This work was supported by the Russian Foundation for Basic Research (project no. 17-0800291). The authors are very thankful to Dr A.S. Ovcharova for helpful discussions and a code for nonstationary problems with interfaces.

\section{References}

[1] D.S.Klyuev, V.M.Fliagin, M.Al-Muzaiqer, N.A.Ivanova, Laser-actuated optofluidic diaphragm capable of optical signal tracking, Applied Physics Letters, 114(2019), 011602.

[2] D.D.Joseph, Stability of fluid motion, Springer, Verlag, 1976.

[3] A.S.Ovcharova, Multilayer system of films heated from above, Int. J. Heat Mass Transfer, 114(2017), 992-1000.

[4] A.S.Ovcharova, V.B.Bekezhanova, Convection regimes induced by local boundary heating in a liquid-gas system, J. Fluid Mech., 873(2019), 441-458.

[5] A.S.Ovcharova, Rupture of liquid film, placed over deep fluid, under action of thermal load, Int. J. Heat Mass Transfer, 78(2014), 294-301.

[6] V.K.Andreev, Yu.A.Gaponenko, O.N.Goncharova, V.V.Pukhnachov, Mathematical models of convection, De Gruyter, Berlin/Boston, 2012.

[7] G.N.Antonow, Sur la tension superficielle à la limite de deux couches, J. Chim. Phys., 5(1907), 372-385. 


\section{Неустойчивость двухслойной системы с деформируемыми границами раздела при нагреве лазерным пучком}

Виктория Б. Бекежанова

Институт вычислительного моделирования СО РАН Академгородок, 50/44, Красноярск, 660036

Россия

Ольга Н. Гончарова

Алтайский государственный университет Ленина, 61, Барнаул, 656049

Россия

Наталья А. Иванова

Денис С. Клюев

Тюменский государственный университет

Володарского, 6, Тюмень, 625003

Россия

Для анализа характеристик течений, возникающих в двухслойной системе под действием интенсивной тепловой нагрузки, индуцированной лазерным пучком на свободной границе, изучается новая нестандартная задача термокапиллярной конвекции. Представлено описание физических экспериментов, параметрами которых являются: отношения толщин жидких слоев, типы рабочих жидкостей, коэффичиенты поглощения сред. Особое внимание в экспериментах уделяется изучению влияния геометрии системы, когда изменяется толщина одного из жидких слоёв. Теоретическое исследование включает построение математической модели, ее апробачию на основе данных физических экспериментов и разработку эффективного численного алгоритма для проведения расчётов. Изучается эволюиия поверхностей раздела и возможсность описания с помощъю предложенной математической модели затухающих колебаний, впервые обнаруженных авторами в экспериментах. Результаты численного исследования структуры и природы конвективных течений в горизонтальной двухслойной системе жидкость-жидкость типа "силиконовое масло-гличерин" и сравнение полученных эксперименталъных и теоретических данных позволяют подтвердить непротиворечивость и адекватность разработанной математической модели, проанализировать особенности тепломассопереноса, обусловленного действием локального теплового источника на верхней свободной гранище.

Ключевые слова: термокапиллярная конвекиия, двухслойная система, граница раздела, свободная поверхность, локальная тепловая нагрузка. 